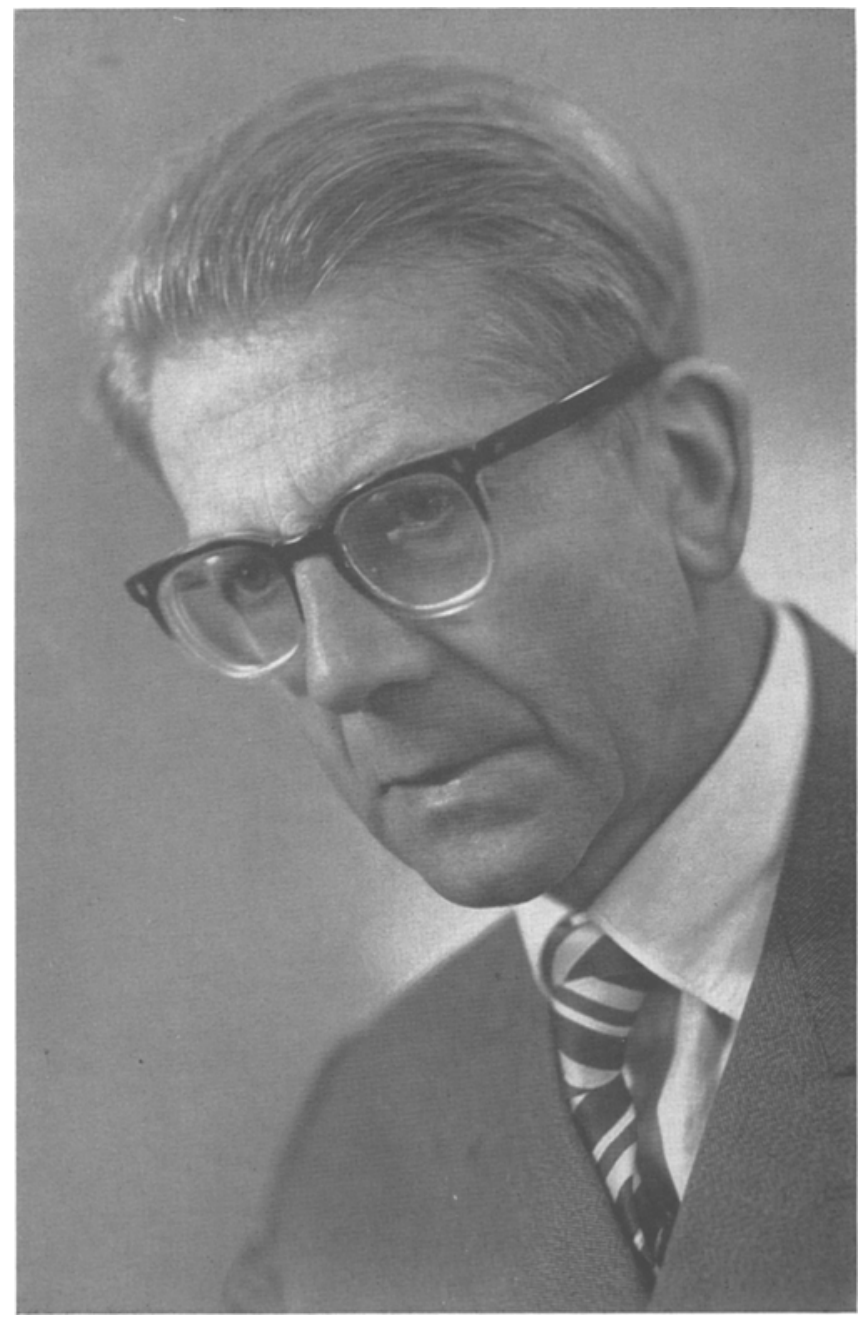

Springer Tracts Modern Physics 40 Springer-Verlag, Berlin - Heidelberg - New York 


\section{Friedrich Hund zum siebzigsten Geburtstag}

Am 4. Februar 1966 vollendete FrIEDRICH HuND in Göttingen sein siebzigstes Lebensjahr. Sei drei Jahrzehnten gehört er zu den Herausgebern der „Ergebnisse", die er gemeinsam mit F. TREndelenbuRG unter den unglïcklichsten Umständen aus den Händen ARNOLD BERLINERS übernahm und durch die schwersten Zeiten hindurch als ein gutes Stück deutscher wissenschaftlicher Tradition rettete. Auch als in den Nachkriegsjahren allmählich ein Neuaufbau der Physik in Deutschland einsetzte, hat er den ,Ergebnissen" die Treue gehalten und an ihrer langsamen Transformation, das gute Alte wahrend und dem guten Neuen aufgeschlossen, mitgewirkt. Wenn er dabei mit zunehmendem Alter die Hauptlast der Arbeit allmählich abstreifte und den Jüngeren überlieB, so wissen doch alle, die aktiv an den „Ergebnissen" mitgearbeitet haben, wieviel sein Rat wog und auch in den letzten zehn Jahren noch zum Gelingen mancher Bände beigetragen hat, wo er selbst im Hintergrunde blieb.

Dem Manne, der entscheidend zum Aufbau der Quantenmechanik seit ihren ersten Anfängen beigetragen hat und zu den ersten großen Interpreten der Molekülstruktur gehörte, dessen Gesamtwerk aber auch klassisch gewordene Arbeiten aus der Physik der festen Körper und der Atomkerne umfaßt;

der einer großen Zahl von Schülern und Freunden in langen Jahren eine nicht abreißende Folge wissenschaftlicher Impulse gegeben hat und menschliches Vorbild gewesen ist;

der in der Sorgfalt, welche er seinen Vorlesungen widmete, und dem Niveau, mit dem er auch elementare Gegenstände zu behandeln verstand, beste deutsche Universitätstradition verkörperte,

sprechen Herausgeber und Verlag der ,Ergebnisse" heute zugleich mit dem Respekt vor seiner Leistung ihren Dank für seine Mitarbeit aus und verbinden diesen mit den besten Wünschen für künftige Jahre des otium cum dignitate, die ihm, nach der Lösung von amtlichen Verpflichtungen, noch eine reiche wissenschaftliche Ernte und menschliches Glück bringen mögen.

S. FLÜGGE 